\title{
Biomarkers for the early detection of anthracycline-induced cardiotoxicity: current status
}

\author{
Jan M. Horacek ${ }^{\mathrm{a}, \mathrm{b}}$, Martina Vasatovac, Radek Pudil ${ }^{\mathrm{d}}$, Milos Tichyc, Pavel Zak ${ }^{\mathrm{b}}$, Martin Jakl ${ }^{\mathrm{a}, \mathrm{d}}$, Ladislav Jebavy ${ }^{\mathrm{a}, \mathrm{b}}$, Jaroslav Maly $^{\mathrm{b}}$
}

Background. Cardiotoxicity is a well-known and potentially serious complication of anticancer therapy. Anthracyclinebased chemotherapy represents the greatest risk. Early detection of cardiotoxicity is crucial for applying preventive and supportive therapeutic strategies.

Methods and Results. Various methods have been recommended for monitoring of cardiotoxicity. In our conditions, echocardiography and electrocardiography are routinely used. However, this approach shows low sensitivity for the early prediction of cardiomyopathy when the possibilities of appropriate management could still improve the patient's outcome. Recently, biomarkers of cardiac injury have been investigated in the assessment of chemotherapy-induced cardiotoxicity. Cardiospecific biomarkers, such as cardiac troponins, show high diagnostic efficacy in the early subclinical phase of the disease before the clinical onset of cardiomyopathy. Increase in their concentrations correlates with disease severity. As for natriuretic peptides, some studies, including ours, have shown promising results. Definitive evidence of their diagnostic and prognostic role in this context is still lacking and natriuretic peptides have not been routinely used for monitoring of cardiotoxicity in clinical practice. Other perspective biomarkers of cardiotoxicity in oncology are under study, especially heart-type fatty acid-binding protein (H-FABP) and glycogen phosphorylase BB (GPBB). Our studies using GPBB have provided encouraging results. However, the available data are limited and their practical use in this context cannot be recommended until their clinical efficacy is clearly defined.

Conclusions. This review covers the current status of biomarkers for the early detection of anthracycline-induced cardiotoxicity. The authors present in brief, their own experience with multiple biomarkers in the detection of cardiotoxicity.

Key words: biomarkers, cardiotoxicity, anthracyclines, chemotherapy

Received: July 7, 2013; Accepted with revision: January 15, 2014; Available online: January 23, 2014 http://dx.doi.org/10.5507/bp.2014.004

${ }^{a}$ Department of Internal Medicine, Faculty of Military Health Sciences, University of Defence, Hradec Kralove, Czech Republic ${ }^{b} 4^{\text {th }}$ Department of Internal Medicine - Hematology, Faculty of Medicine in Hradec Kralove, Charles University in Prague and University Hospital Hradec Kralove

cInstitute of Clinical Biochemistry and Diagnostics, University Hospital Hradec Kralove

${ }^{d}{ }^{\text {st }}$ Department of Internal Medicine - Cardioangiology, Faculty of Medicine in Hradec Kralove, Charles University in Prague and University Hospital Hradec Kralove

Corresponding author: Jan M. Horacek, e-mail: horacek@pmfhk.cz

\section{INTRODUCTION}

Cardiotoxicity is a well-known and potentially serious complication of anticancer therapy that can significantly impair the patient's quality of life and substantially increase health care costs. A wide range of chemotherapeutic agents are associated with cardiotoxicity. Of these, anthracyclines represent the greatest risk for development of cardiotoxicity. Despite conflicting reports, proposed risk factors for anthracycline cardiotoxicity include: 1 . cumulative dose of the drug (the most important and independent risk factor), 2. age under 3 years or over 65 years, 3. irradiation of the mediastinum, 4. combination with other cardiotoxic chemotherapy (CT), 5 . female gender, 6 . heart damage caused by another disease (coronary atherosclerosis, arterial hypertension, diabetes mellitus, valvular heart disease), 7. bolus administration of the drug ${ }^{1-3}$. High-dose chemotherapy (HD-CT) especially regimens containing high-dose Cyclophosphamide are also associated with high risk for development of cardiotoxicity ${ }^{46}$.
In general, two forms of CT-induced cardiotoxicity ${ }^{7}$ may be distinguished: (1) Acute and subacute cardiotoxicity, found less frequently, can occur anytime from the initiation of CT up to 2 weeks after termination of treatment. In this form, the most common clinical findings range from abnormalities in ventricular repolarization and QT interval changes to supraventricular and ventricular arrhythmias or to acute coronary syndromes, acute heart failure, and pericarditis/myocarditis-like syndromes. (2) Chronic cardiotoxicity, the most frequent cumulative dose-dependent form, may be differentiated into 2 subtypes based on the timing of onset of clinical symptoms: early, within 1 year of the termination of CT, and late, after 1 year. The most typical sign of chronic cardiotoxicity is asymptomatic systolic and/or diastolic left ventricular (LV) dysfunction that leads to severe congestive cardiomyopathy and may eventually lead to death. The incidence of chronic cardiotoxicity depends on the presence of risk factors, time of follow-up, criteria used for cardiotoxicity definition and diagnostic methods used for cardiotoxicity identification, ranging in different studies from 5 to 
$65 \%$ of patients ${ }^{7-10}$. Anthracycline-induced cardiotoxicity is often divided into 4 subgroups: acute, subacute, chronic (occurring within 1 year of treatment) and late-onset (occurring more than 1 year after the completion of treatment).

\section{DIAGNOSTIC METHODS FOR IDENTIFICATION OF CT-INDUCED CARDIOTOXICITY}

Early identification of patients at risk for cardiotoxicity represents a primary goal for cardiologists and oncologists, considering personalized anticancer therapeutic strategies or interventions ${ }^{11}$. For the detection of subclinical myocardial damage, time and expensive monitoring of cardiac functions is still recommended during and after CT ( ref. $^{7,12,13}$ ). Nevertheless, most of the approaches commonly used in clinical practice - evaluation of left ventricular ejection fraction (LVEF) by echocardiography or radionuclide ventriculography ${ }^{14-19}$ - showed low diagnostic sensitivity and low predictive power in detecting subclinical myocardial injury ${ }^{9,20}$. The use of some other techniques, such as endomyocardial biopsy, is troublesome in clinical practice owing to the invasiveness of the techniques $^{12,13,21}$.

Thus, there is a growing expectation for newer, noninvasive and cost-effective diagnostic tools for the early identification of patients susceptible to developing CTinduced cardiotoxicity ${ }^{22}$. The use of easily detectable cardiac biomarkers in blood has been evaluated in animal models and clinical studies ${ }^{23-27}$. Screening of high-risk patients is recommended for the detection of early subclinical cardiotoxicity.

Evaluation of cardiac biomarkers capable to specifically detect myocardial injury and to predict LV dysfunction could represent an alternative diagnostic tool for the early detection of cardiotoxicity ${ }^{28}$. Previous reports consistently laid the theoretical basis for the possible use of cardiac troponins and natriuretic peptides in the early detection of cardiotoxicity in clinical practice, whereas creatine kinase $\mathrm{MB}$ (CK-MB) does not seem to be effective owing to a short time window of the serum elevation after myocardial injury and its imperfect cardiac specificity and sensitivity ${ }^{29-31}$.

In 2011, a position statement from the Heart Failure Association of the European Society of Cardiology on "Cardiovascular side effects of cancer therapies" was published $^{32}$. The main recommendations among others include that identification and validation of reliable biomarkers for the prediction and detection of cardiotoxicity of chemotherapeutic agents is urgently required. The use of simple biomarkers such as troponins and natriuretic peptides should be strongly considered but is not a substitute for objective evaluation by echocardiography or similar modalities. When designing clinical trials with potentially cardiotoxic agents, the routine use of currently available biomarkers (e.g. troponins and natriuretic peptides) should be strongly considered and their validation incorporated into the trial design, if possible.
The Expert Working Group on Biomarkers of DrugInduced Cardiac Toxicity developed the following list of characteristics of "ideal biomarkers", which includes specificity, sensitivity, kinetics of appearance in accessible media, robust assay, and ability to bridge between preclinical and clinical applications ${ }^{33}$.

On this basis, we performed an analysis of the available scientific literature to define the clinical usability of cardiac biomarkers for the early detection of cardiotoxicity in oncology.

\section{Cardiac troponins as markers of CT-induced cardiotoxicity}

The clinical application of cardiac troponins as cardiotoxicity biomarkers was analyzed in several clinical studies with a consistent number of subjects monitored by cardiac troponin I (cTnI) or cardiac troponin T (cTnT), for the total number of almost 1500 adult patients treated with CT for cancer ${ }^{34-40}$. The evidence emerging from these studies is that the percentage of patients with positive troponin values ranges from 15 to $34 \%$. Thus, the increase in troponin concentrations in the blood underlines the occurrence of irreversible myocardial cell injury in patients treated with potentially cardiotoxic CT.

In our study on 23 patients treated with anthracyclinebased CT for acute leukemia (mean age $47.0 \pm 11.1$ years, 14 males, mean total cumulative anthracycline dose 472.1 $\pm 115.0 \mathrm{mg} / \mathrm{m}^{2}$ ), cTnI became positive in $17.4 \%$ patients during CT and in $26.1 \%$ patients within 6 months after completion of CT. Our results suggest that evaluation of cTnI - in contrast with cTnT - during anthracycline treatment could identify patients at risk for development of anthracycline-induced cardiomyopathy in the future. CTnI seems to be superior to cTnT in the early detection of cardiac injury associated with anthracycline treatment in acute leukemia. The possible explanation could be the difference in molecular weight and release kinetics of cTnI and cTnT. Based on our preliminary data, a larger prospective and multicenter study would be most desirable ${ }^{41}$.

The agreement in defining the cut-off values for cardiac troponins (concentration measured with an analytic imprecision expressed as the coefficient of variation $\leq$ $10 \%)$, despite the availability of several methods for troponin determination, would lead to a useful unification of the definition of positive troponin results for the detection of myocardial injury related to cardiotoxicity. This cut-off provides the highest level of sensitivity for detection of myocardial injury at an acceptable level of analytic reliability. Adopting a univocal definition of positivity makes the troponin test very useful in clinical practice to monitor cardiac injury independent of the method used and of the laboratory performing the assay.

In contrast, the sampling protocol used in different studies is not as homogeneous as expected ${ }^{25}$. It is important to note that the increase of troponin concentrations was detected at different intervals after administration of CT in various studies indicating that it may be necessary to collect several blood samples to demonstrate the possible increase of the marker ${ }^{42}$. 
Clinical evidence derived from published studies can be summarized as follows: (1) Troponin determination is able to predict the occurrence of a clinically significant LV dysfunction at least 3 months in advance ${ }^{35,40}$. (2) The early increase in the troponin concentrations also predicts the degree and severity of LV dysfunction in the future ${ }^{35,38}$. (3) Among patients with positive troponin values, persistence of the increase within 1 month after the last CT is related to $85 \%$ probability of major cardiac events within the first year of the follow-up ${ }^{38,43}$. (4) A persistently negative troponin test result can identify patients with the lowest cardiotoxicity risk (negative predictive value of 99\%), who will not encounter cardiac complications at least within the first year after completion of CT.

From this scientific evidence, we can derive the main practical advantages of the use of troponin testing as a biomarker of cardiotoxicity, especially when it is compared with the low efficacy of any other method currently applied in this clinical setting: (1) Troponin determination detects the presence of cardiotoxicity very early, significantly before impairment of cardiac functions can be revealed by any other diagnostic method. (2) Immediately after the last CT, troponin determination allows the discrimination of patients at low risk from patients at high risk for cardiotoxicity requiring more careful long-term cardiac monitoring by imaging techniques.

The role of cardiac troponin determination to stratify the risk of cardiotoxicity is currently based on strong evidence clearly suggesting the routine use of this biomarker ${ }^{44}$. Cardiac troponins have been incorporated into National Cancer Institute (NCI) classification of cardiotoxicity of anticancer therapy (Common Terminology Criteria for Adverse Events, CTCAE).

\section{Natriuretic peptides as markers of CT-induced cardiotoxicity}

Natriuretic peptides - atrial natriuretic peptide (ANP), brain natriuretic peptide (BNP) and N-terminal pro brain natriuretic peptide (NT-proBNP) - are produced by the myocardium in response to wall strain and pressure overload. ANP is produced mainly in atria, BNP/ NT-proBNP predominantly in ventricles. In cardiology, natriuretic peptides are routinely used in diagnostics and management of cardiac dysfunction and heart failure ${ }^{45-47}$. Normal plasma BNP/NT-proBNP concentrations practically exclude heart failure due to high negative predictive value of the test ${ }^{48,49}$.

The applicability of natriuretic peptides (ANP, BNP, NT-proBNP) as markers for anthracycline-induced cardiotoxicity has been investigated in a limited number of studies. The results of some studies have suggested that natriuretic peptides could be of value in the detection of clinical and subclinical cardiotoxicity of anthracyclines $^{50-54}$.

In our very first study, we evaluated the acute cardiotoxicity of the anthracycline agent, Idarubicin in induction CT for acute myeloid leukemia (15 patients, mean age $43.7 \pm 10.6$ years, 9 males). Our results suggested that induction CT for acute myeloid leukemia (Idarubicin $36 \mathrm{mg} / \mathrm{m}^{2}$ and intermediate doses of Cytarabine) is in all patients associated with acute neurohumoral activation (transient elevation of NT-proBNP) indicating acute subclinical cardiotoxicity. One patient experienced clinical cardiotoxicity within 2 weeks after induction CT. Since NT-proBNP elevations preceded the development of congestive heart failure after induction CT, we concluded that NT-proBNP seems to be a promising early marker and predictor of this complication. Hence, we suggest that serial measurements of plasma NT-proBNP could aid the early detection of cardiac dysfunction during anthracycline-based CT. Whether these acute changes are able to predict chronic and late cardiotoxicity is not clear. Studies are warranted in a greater number of patients and in patients with higher cumulative doses of anthracyclines and other risk factors for the development of anthracycline cardiotoxicity $^{55}$.

In another study, we evaluated acute and chronic cardiotoxicity of anthracyclines in 26 patients treated for acute leukemia (mean age $46.2 \pm 12.4$ years, 15 males, mean total cumulative anthracycline dose $464.3 \pm 117.5$ $\mathrm{mg} / \mathrm{m}^{2}$ ). Our results showed that anthracycline-based CT is associated with acute and chronic neurohumoral activation of cardiac dysfunction that is manifested by a significant increase in NT-proBNP. NT-pro BNP correlated with LV dysfunction on echocardiography. It seems that NT-proBNP could be useful in the early detection of anthracycline-induced cardiotoxicity. Further studies on a larger number of patients and with a longer follow-up will be needed ${ }^{56}$.

Recently published studies reported significant BNP/ NT-proBNP elevations after HD-CT and hematopoietic cell transplantation ${ }^{57-60}$. Persistent BNP/NT-proBNP elevations early after HD-CT were observed in $33-47 \%$ patients and were associated with the development of cardiac dysfunction during the follow-up. The results suggest that monitoring of BNP/NT-proBNP could identify patients at risk for development of cardiac dysfunction after HD-CT and hematopoietic cell transplantation.

On the other hand, some studies using natriuretic peptides in the detection of CT-induced cardiotoxicity reported limited clinical usefulness of this method ${ }^{26,61,62}$.

The published data are quite heterogeneous and often incomplete, lacking crucial information such as the ratio of patients with increased natriuretic peptide values, the methods used to measure natriuretic peptides and the cutoff values associated with the best diagnostic accuracy. Regarding the methods used to detect the occurrence of cardiac dysfunction, several articles reported the use of echocardiography or radionuclide ventriculography. Some authors studied the association and relationship between natriuretic peptides and diastolic LV dysfunction, and others simply checked systolic LV function. However, only a few studies ${ }^{55,63-67}$ evaluated the potential predictive value of natriuretic peptide concentrations to detect the ongoing development of cardiac dysfunction.

A lack of agreement in the conclusions of different studies is evident. Overall, studies were unable to confirm definitively the clinical usefulness of natriuretic peptides as cardiotoxicity biomarkers. 
Even though there are some promising data available, it is not currently possible to recommend the routine use of the natriuretic peptides for monitoring of cardiotoxicity in clinical practice. New prospective studies on large cohorts of patients using validated, commercially available assays and comparing natriuretic peptides with wellestablished markers of cardiotoxicity are needed.

\section{Perspective markers of CT-induced cardiotoxicity (under study)}

Other potential markers of cardiotoxicity in oncology are under study, especially heart-type fatty acid-binding protein (H-FABP) and glycogen phosphorylase BB (GPBB).

H-FABP and GPBB are newer perspective markers for the early detection of myocardial ischemia and necrosis, recently evaluated in the diagnostics and risk stratification of acute coronary syndromes ${ }^{68-71}$. H-FABP is a relatively small cytoplasmic protein for the oxidation of fatty acids that is quite specific for cardiac muscle. H-FABP is rapidly released from the myocardium after ischemic injury into the bloodstream. Plasma H-FABP increases above the reference limit within 2-3 h of the onset of myocardial injury and returns to normal values within $18-30 \mathrm{~h}$. GPBB is a glycogenolytic enzyme providing glucose for the heart muscle tissue. During glycogenolysis in ischemic tissue, GPBB is released from the sarcoplasmic reticulum into the cytoplasm and then into the circulation through the damaged cell membrane. GPBB is released into the circulation 2-4 h after myocardial injury, returning to normal values within 24-36 h of damage occurrence. In the acute coronary syndrome setting, both markers are regarded as early markers of cardiac injury due to acute myocardial ischemia. The main mechanism of cardiac injury caused by anticancer therapy is mainly non-ischemic and prior cyclic exposure to anthracycline agents may play a role (chronic and late cardiotoxicity). Therefore, it is difficult to estimate the kinetics of release of these biomarkers from cardiomyocytes in this setting. Experience with these perspective biomarkers in the assessment of cardiotoxicity of anticancer therapy is very limited.

ElGhandour et al. ${ }^{72}$ studied H-FABP in 40 non-Hodgkin's lymphoma patients treated with 6 cycles of CT containing Doxorubicin (cumulative dose $300 \mathrm{mg} / \mathrm{m}^{2}$ ). The authors concluded that H-FABP may serve as a reliable early marker for prediction of cardiomyopathy induced by Doxorubicin.

Since 2007, we have published several papers dealing with multiple biomarkers of cardiac injury, including GPBB and H-FABP, to detect cardiotoxicity associated with CT for hematological malignancies - conventional CT containing anthracyclines and HD-CT followed by hematopoietic cell transplantation ${ }^{73-78}$.

In our study on 24 acute leukemia patients treated with anthracycline-based CT (mean age $48.1 \pm 10.9$ years, 13 males, mean total cumulative anthracycline dose 463.2 $\pm 114.3 \mathrm{mg} / \mathrm{m}^{2}$ ), we found significant elevations in GPBB after CT containing anthracyclines (in $16.7 \%$ and $20.8 \%$ patients, respectively). Increased release of GPBB from cardiomyocytes after administration of CT could be con- sidered a sign of acute subclinical cardiotoxicity. Positivity of GPBB in patients with negativity of other cardiac biomarkers suggests that GPBB could be a more sensitive and promising marker for detection of acute cardiac injury caused by anthracycline-based CT, probably superior to cardiac troponins. Whether these acute changes will predict a development of cardiomyopathy in the future is not known and will be evaluated during a prospective follow-up. Further studies in a larger number of patients will be needed to define the potential role of new circulating biomarkers in the assessment of anthracycline-induced cardiotoxicity $^{75}$.

Other molecules have been proposed as markers for cardiovascular injury related to CT-induced toxic effect. Increase in markers of inflammation, such as cytokines, has also been described after CT. Mercuro et al. ${ }^{79}$ and Mantovani et al. ${ }^{80}$ reported a correlation between interleukine-6 increase and early changes in systolic LV function when analyzed by tissue Doppler imaging in a small sample of patients treated with Epirubicin containing CT. These preliminary results warrant confirmation by further investigations on a larger number of patients for a longer period of follow-up.

Several clinical studies have also analyzed endothelial damage in cancer patients. Nuver et al.$^{81}$ reported an increased level of endothelial dysfunction markers in patients treated with CT several years before. Vaughn et al. ${ }^{82}$ also reported that long-term cancer survivors treated with CT showed increased markers of endothelial injury. These findings suggest that CT may induce endothelial dysfunction and accelerate atherosclerotic processes leading to an increased risk for future cardiovascular diseases ${ }^{83}$. However, at present, no correlation with long-term cardiovascular events has been demonstrated and the predictive role of these markers is still unknown.

\section{CONCLUSIONS}

CT is a well-established therapeutic approach for several malignancies, but its clinical efficacy is often limited by CT-related cardiotoxicity which may lead to cardiomyopathy possibly evolving into heart failure. The most frequently adopted diagnostic method for detection of cardiac injury is evaluation of LVEF by echocardiography or radionuclide ventriculography. However, this approach shows low sensitivity for the early prediction of cardiomyopathy when appropriate management could improve the patient's outcome.

Cardiospecific biomarkers, such as cardiac troponins, show high diagnostic efficacy in the early subclinical phase of the disease, before the clinical onset of cardiomyopathy. The increase in their concentrations correlates with disease severity and may predict the occurrence of major cardiac events during follow-up. Negative troponin concentrations may identify patients with a low risk of cardiomyopathy. The role of cardiac troponin determination to stratify the risk of cardiotoxicity is currently based on strong evidence suggesting the routine use of this biomarker. Recently, natriuretic peptides have been investigated 
in detection of CT-induced cardiotoxicity. Some studies, including ours, have shown promising results. However, definitive evidence of their diagnostic and prognostic role in this context is still lacking and natriuretic peptides have not been routinely used for monitoring of cardiotoxicity in clinical practice. Other perspective biomarkers of cardiotoxicity in oncology are under study, especially H-FABP and GPBB. Based on our data, a larger prospective and multicenter study will be needed to define the potential role of GPBB and other proposed biomarkers of cardiac injury in the assessment of cardiotoxicity induced by chemotherapeutic agents.

\section{ABBREVIATIONS}

ANP, Atrial natriuretic peptide; BNP, Brain natriuretic peptide; CK-MB, Creatine kinase MB; CT, Chemotherapy; cTnI, Cardiac troponin I; cTnT, Cardiac troponin T; GPBB, Glycogen phosphorylase BB; HD-CT, High-dose chemotherapy; H-FABP, Heart-type fatty acidbinding protein; LV, Left ventricular; LVEF, Left ventricular ejection fraction; NT-proBNP, N-terminal pro brain natriuretic peptide.

\section{ACKNOWLEDGMENTS}

The work was supported by a long-term organization development plan 1011 (Faculty of Military Health Sciences, Hradec Kralove) and by research projects MO 0FVZ0000503 and MZO 00179906.

Authorship contributions: JMH, LJ: literature search; JMH, RP, PZ: manuscript writing; JMH, RP: study design; JMH, MJ: data collection; MV, MT: laboratory procedures (data analysis); MJ: statistical analysis; JMH, PZ, JM: data interpretation; all authors: final revision.

Conflict of interest statement: None declared.

\section{REFERENCES}

1. Shan K, Lincoff AM, Young JB. Anthracycline-induced cardiotoxicity Ann Intern Med 1996;125:47-58.

2. Jones RL, Swanton C, Ewer MS. Anthracycline cardiotoxicity. Expert Opin Drug Saf 2006;5:791-809.

3. Sawyer DB, Peng X, Chen B, Pentassuglia L, Lim CC. Mechanisms of anthracycline cardiac injury: can we identify strategies for cardioprotection? Prog Cardiovasc Dis 2010;53:105-13.

4. Senkus E, Jassem J. Cardiovascular effects of systemic cancer treatment. Cancer Treat Rev 2011;37:300-11.

5. Morandi P, Ruffini PA, Benvenuto GM, Raimondi R, Fosser V. Cardiac toxicity of high-dose chemotherapy. Bone Marrow Transplant 2005;35:323-34

6. Yeh ET, Tong AT, Lenihan DJ, Yusuf SW, Swafford J, Champion C, Durand JB, Gibbs H, Zafarmand AA, Ewer MS. Cardiovascular complications of cancer therapy: diagnosis, pathogenesis and management. Circulation 2004;109:3122-31.

7. Pai VB, Nahata MC. Cardiotoxicity of chemotherapeutic agents: incidence, treatment and prevention. Drug Saf 2000;22:263-302.

8. Singal PK, lliskovic N. Doxorubicin-induced cardiomyopathy. N Engl J Med 1998;339:900-5.

9. Jensen BV, Skovsgaard T, Nielsen SL. Functional monitoring of anthracycline cardiotoxicity: a prospective blinded long-term observational study of outcome in 120 patients. Ann Oncol 2002;13:699-709.
10. Lipshultz SE, Lipsitz SR, Mone SM, Goorin AM, Sallan SE, Sanders SP, Orav EJ, Gelber RD, Colan SD. Female sex and drug dose as risk factors for late cardiotoxic effects of doxorubicin therapy for childhood cancer. N Engl J Med 1995;332:1738-43.

11. Wouters KA, Kremer LC, MillerTL, Herman EH, Lipshultz SE. Protecting against anthracycline-induced myocardial damage: a review of the most promising strategies. Br J Haematol 2005;131:561-78.

12. Gharib MI, Burnett AK. Chemotherapy-induced cardiotoxicity: current practice and prospects of prophylaxis. Eur J Heart Fail 2002:4:235-42.

13. Ganz WI, Sridhar KS, Ganz SS, Gonzalez R, Chakko S, Serafini A. Review of tests for monitoring doxorubicin induced cardiomyopathy. Oncology 1996;53:461-70.

14. Steinherz LJ, Graham T, Hurwitz R, Sondheimer HM, Schwartz RG, Shaffer EM, Sandor G, Benson L, Williams R. Guidelines for cardiac monitoring of children during and after anthracycline therapy: report of the Cardiology Committee of the Childrens Cancer Study Group. Pediatrics 1992;89:942-9.

15. Lipshultz SE, Sanders SP, Goorin AM, Krischer JP, Sallan SE, Colan SD Monitoring for anthracycline cardiotoxicity. Pediatrics 1994;93:4337.

16. Ritchie JL, Bateman TM, Bonow RO, Crawford MH, Gibbons RJ, Hall RJ, O'Rourke RA, Parisi AF, Verani MS. Guidelines for clinical use of cardiac radionuclide imaging: report of the American College of Cardiology/American Heart Association Task Force on assessment of diagnostic and therapeutic cardiovascular procedures, in collaboration with the American Society of Nuclear Cardiology. J Am Coll Cardiol 1995:25:521-47.

17. Mitani I, Jain D, Joska TM, Burtness B, Zaret BL. Doxorubicin cardiotoxicity: prevention of congestive heart failure with serial cardiac function monitoring with equilibrium radionuclide angiocardiography in the current era. J Nucl Cardiol 2003;10:132-9.

18. Sabel MS, Levine EG, Hurd T, Schwartz GN, Zielinski R, Hohn D, Edge SB. Is MUGA scan necessary in patients with low-risk breast cancer before doxorubicin-based adjuvant therapy? Am J Clin Oncol 2001;24:425-8.

19. Jiji RS, Kramer CM, Salerno M. Non-invasive imaging and monitoring cardiotoxicity of cancer therapeutic drugs. J Nucl Cardiol 2012;19:377-88.

20. Cardinale D, Colombo A, Lamantia G, Colombo N, Civelli M, De Giacomi G, Rubino M, Veglia F, Fiorentini C, Cipolla CM. Anthracycline-induced cardiomyopathy: clinical relevance and response to pharmacologic therapy. J Am Coll Cardiol 2010;55:213-20.

21. Meinardi MT, van der Graaf WT, van Veldhuisen DJ, Gietema JA, de Vries EG, Sleijfer DT. Detection of anthracycline-induced cardiotoxicity. Cancer Treat Rev 1999;25:237-47.

22. Benvenuto GM, Ometto R, Fontanelli A, Fortunato A, Ruffini PA Fosser V, Morandi P. Chemotherapy-related cardiotoxicity: new diagnostic and preventive strategies. Ital Heart J 2003;4:655-67.

23. Sparano JA, Brown DL, Wolff AC. Predicting cancer therapy-induced cardiotoxicity: the role of troponins and other markers. Drug Saf 2002;25:301-11.

24. Adamcova M, Sterba M, Simunek T, Potacova A, Popelova O, Mazurova Y, GersI V. Troponin as a marker of myocardiac damage in drug-induced cardiotoxicity. Expert Opin Drug Saf 2005;4:457-72.

25. Bryant J, Picot J, Baxter L, Levitt G, Sullivan I, Clegg A. Use of cardiac markers to assess the toxic effects of anthracyclines given to children with cancer: a systematic review. Eur J Cancer 2007:43:1959-66.

26. Mavinkurve-Groothuis AM, Kapusta L, Nir A, Groot-Loonen J. The role of biomarkers in the early detection of anthracycline-induced cardiotoxicity in children: a review of the literature. Pediatr Hematol Oncol 2008;25:655-64.

27. Urbanova D, Urban L, Danova K, Simkova I. Natriuretic peptides: biochemical markers of anthracycline cardiac toxicity? Oncol Res 2008;17:51-58.

28. Morandi P, Ruffini PA, Benvenuto GM, Raimondi R, Fosser V. Cardiac toxicity of high-dose chemotherapy. Bone Marrow Transplant 2005;35:323-34.

29. Herman EH, Zhang J, Lipshultz SE, Rifai N, Chadwick D, Takeda K, Yu ZX, Ferrans VJ. Correlation between serum levels of cardiac troponin $T$ and the severity of the chronic cardiomyopathy induced by doxorubicin. J Clin Oncol 1999;17:2237-43.

30. Koh E, Nakamura T, Takahashi H. Troponin T and brain natriuretic peptide as predictors for adriamycin-induced cardiomyopathy in rats. Circ J 2004;68:163-7 
31. Kral M, Skoloudik D, Sanak D, Veverka T, Bartkova A, Dornak T, Hutyra M, Vindis D, Ulehlova J, Slavik L, Svabova M, Kubickova V, Herzig R, Kanovsky P. Assessment of relationship between acute ischemic stroke and heart disease - protocol of a prospective observational trial. Biomed Pap Med Fac Univ Palacky Olomouc Czech Repub 2012;156:284-9.

32. Eschenhagen T, Force T, Ewer MS, de Keulenaer GW, Suter TM, Anker SD, Avkiran M, de Azambuja E, Balligand JL, Brutsaert DL, Condorell G, Hansen A, Heymans S, Hill JA, Hirsch E, Hilfiker-Kleiner D, Janssens $S$, de Jong S, Neubauer G, Pieske B, Ponikowski P, Pirmohamed M Rauchhaus M, Sawyer D, Sugden PH, Wojta J, Zannad F, Shah AM Cardiovascular side effects of cancer therapies: a position statement from the Heart Failure Association of the European Society of Cardiology. Eur J Heart Fail 2011;13:1-10.

33. Wallace KB, Hausner E, Herman E, Holt GD, MacGregor JT, Metz AL, Murphy E, Rosenblum IY, Sistare FD, York MJ. Serum troponins as biomarkers of drug-induced cardiac toxicity. Toxicol Pathol 2004;32:10621.

34. Cardinale D, Sandri MT, Martinoni A, Tricca A, Civelli M, Lamantia G, Cinieri S, Martinelli G, Cipolla CM, Fiorentini C. Left ventricular dysfunction predicted by early troponin I release after high-dose chemotherapy. J Am Coll Cardiol 2000;36:517-22.

35. Cardinale D, Sandri MT, Martinoni A, Borghini E, Civelli M, Lamantia G, Cinieri S, Martinelli G, Fiorentini C, Cipolla CM. Myocardial injury revealed by plasma troponin I in breast cancer treated with highdose chemotherapy. Ann Oncol 2002;13:710-5.

36. Sandri MT, Cardinale D, Zorzino L, Passerini R, Lentati $P$, Martinoni A, Martinelli G, Cipolla CM. Minor increases in plasma troponin predict decreased left ventricular ejection fraction after high-dose chemotherapy. Clin Chem 2003;49:248-52.

37. Auner HW, Tinchon C, Linkesch W, Tiran A, Quehenberger F, Link H, Sill $\mathrm{H}$. Prolonged monitoring of troponin T for the detection of anthracycline cardiotoxicity in adults with hematological malignancies. Ann Hematol 2003;82:218-22.

38. Cardinale D, Sandri MT, Colombo A, Colombo N, Boeri M, Lamantia G, Civelli M, Peccatori F, Martinelli G, Fiorentini C, Cipolla CM. Prognostic value of troponin I in cardiac risk stratification of cancer patients undergoing high-dose chemotherapy. Circulation 2004;109:2749-54.

39. Lipshultz SE, Rifai N, Dalton VM, Levy DE, Silverman LB, Lipsitz SR Colan SD, Asselin BL, Barr RD, Clavell LA, Hurwitz CA, Moghrabi A, Samson Y, Schorin MA, Gelber RD, Sallan SE. The effects of dexrazoxane on myocardial injury in doxorubicin-treated children with acute lymphoblastic leukemia. N Engl J Med 2004;351:145-53.

40. Kilickap S, Barista I, Akgul E, Aytemir K, Aksoyek S, Aksoy S, Celik I, Kes S, Tekuzman G. cTnT can be a useful marker for early detection of anthracycline cardiotoxicity. Ann Oncol 2005;16:798-804.

41. Horacek JM, Pudil R, Tichy M, Jebavy L, Strasova A, Ulrychova M, Zak P, Maly J. Cardiac troponin I seems to be superior to cardiac troponin $\mathrm{T}$ in the early detection of cardiac injury associated with anthracycline treatment. Onkologie 2008;31:559-60.

42. Auner HW, Tinchon C, Quehenberger F, Linkesch W, Sill H. Troponins in prediction of cardiotoxic effects. Lancet 2001;357:808.

43. Cardinale D, Lamantia G, Cipolla CM. Troponin I and cardiovascular risk stratification in patients with testicular cancer. J Clin Onco 2006;24:3508-14

44. Dolci A, Dominici R, Cardinale D, Sandri MT, Panteghini M. Biochemical markers for prediction of chemotherapy-induced cardiotoxicity: Systematic review of the literature and recommendations for use. Am J Clin Pathol 2008;130:688-95.

45. McMurray JJ, Adamopoulos S, Anker SD, Auricchio A, Böhm M Dickstein K, Falk V, Filippatos G, Fonseca C, Gomez-Sanchez MA Jaarsma T, Køber L, Lip GY, Maggioni AP, Parkhomenko A, Pieske BM, Popescu BA, Rønnevik PK, Rutten FH, Schwitter J, Seferovic P, Stepinska J, Trindade PT, Voors AA, Zannad F, Zeiher A; ESC Committee for Practice Guidelines. ESC Guidelines for the diagnosis and treatment of acute and chronic heart failure 2012: The Task Force for the Diagnosis and Treatment of Acute and Chronic Heart Failure 2012 of the European Society of Cardiology. Developed in collaboration with the Heart Failure Association (HFA) of the ESC. Eur Heart J 2012;33:1787-847.

46. Clerico A, Fontana M, Zyw L, Passino C, Emdin M. Comparison of the diagnostic accuracy of brain natriuretic peptide (BNP) and the $\mathrm{N}$-terminal part of the propeptide of BNP immunoassays in chronic and acute heart failure: a systematic review. Clin Chem 2007;53:81322.
47. Kotaska K, Prusa R. Evidence for natriuretic peptides A and B as noninvasive markers in congenital and valvular heart disease. Biomed Pap Med Fac Univ Palacky Olomouc Czech Repub 2010;154:21-4.

48. Cowie MR, Jourdain $P$, Maisel A, Dahlstrom U, Follath F, Isnard $R_{\text {, }}$ Luchner A, McDonagh T, Mair J, Nieminen M, Francis G. Clinical application of B-type natriuretic peptide (BNP) testing. Eur Heart J 2003;24:1710-8.

49. Hess G, Runkel S, Zdunek D, Hitzler WE. N-terminal pro-brain natriuretic peptide (NT-proBNP) in healthy blood donors and in patients from general practitioners with and without a diagnosis of cardiac disease. Clin Lab 2005;51:167-72.

50. Bauch M, Ester A, Kimura B, Victorica BE, Kedar A, Phillips MI. Atria natriuretic peptide as a marker for doxorubicin-induced cardiotoxic effects. Cancer 1992;69:1492-7.

51. Suzuki T, Hayashi D, Yamazaki T, Mizuno T, Kanda Y, Komuro I, Kurabayashi M, Yamaoki K, Mitani K, Hirai H, Nagai R, Yazaki Y. Elevated B-type natriuretic peptide levels after anthracycline administration. Am Heart J 1998;136:362-3.

52. Hayakawa H, Komada Y, Hirayama M, Hori H, Ito M, Sakurai M. Plasma levels of natriuretic peptides in relation to doxorubicin-induced cardiotoxicity and cardiac function in children with cancer. Med Pediatr Oncol 2001;37:4-9.

53. Erkus B, Demirtas S, Yarpuzlu AA, Can M, Genc Y, Karaca L. Early prediction of anthracycline induced cardiotoxicity. Acta Paediatr 2007;96:506-9.

54. Ekstein S, Nir A, Rein AJ, Perles Z, Bar-Oz B, Salpeter L, Algur N, Weintraub M. N-terminal-proB-type natriuretic peptide as a marker for acute anthracycline cardiotoxicity in children. J Pediatr Hematol Oncol 2007;29:440-4.

55. Horacek JM, Pudil R, Tichy M, Jebavy L, Strasova A, Praus R, Zak P, Maly J. The use of biochemical markers in cardiotoxicity monitoring in patients treated for leukemia. Neoplasma 2005;52:430-4.

56. Horacek JM, Pudil R, Jebavy L, Tichy M, Zak P, Maly J. Assessment of anthracycline-induced cardiotoxicity with biochemical markers. Exp Oncol 2007;29:309-13.

57. Sandri MT, Salvatici M, Cardinale D, Zorzino L, Passerini R, Lentati $P$ Leon M, Civelli M, Martinelli G, Cipolla CM. N-terminal pro-B-type natriuretic peptide after high-dose chemotherapy: a marker predictive of cardiac dysfunction? Clin Chem 2005;51:1405-10.

58. Snowden JA, Hill GR, Hunt P, Carnoutsos S, Spearing RL, Espiner E, Hart DN. Assessment of cardiotoxicity during haemopoietic stem cell transplantation with plasma brain natriuretic peptide. Bone Marrow Transplant 2000;26:309-13.

59. Niwa N, Watanabe E, Hamaguchi M, Kodera Y, Miyazaki H, Kodama I, Ohono M. Early and late elevation of plasma atrial and brain natriuretic peptides in patients after bone marrow transplantation. Ann Hematol 2001;80:460-5.

60. Horacek JM, Pudil R, Tichy M, Jebavy L, Zak P, Slovacek L, Maly J. Biochemical markers and assessment of cardiotoxicity during preparative regimen and hematopoietic cell transplantation in acute leukemia. Exp Oncol 2007;29:243-7.

61. Poutanen T, Tikanoja T, Riikonen P, Silvast A, Perkkiö M. Long-term prospective follow-up study of cardiac function after cardiotoxic therapy for malignancy in children. J Clin Oncol 2003;21:2349-56.

62. Daugaard G, Lassen U, Bie P, Pedersen EB, Jensen KT, Abildgaard U, Hesse B, Kjaer A. Natriuretic peptides in the monitoring of anthracycline induced reduction in left ventricular ejection fraction. Eur J Heart Fail 2005;7:87-93.

63. Nousiainen T, Jantunen E, Vanninen E, Remes J, Vuolteenaho O, Hartikainen J. Natriuretic peptides as markers of cardiotoxicity during doxorubicin treatment for non-Hodgkin's lymphoma. Eur J Haematol 1999;62:135-41.

64. Okumura H, luchi K, Yoshida T, Nakamura S, Takeshima M, Takamatsu H, Ikeno A, Usuda K, Ishikawa T, Ohtake S, Matsuda T. Brain natriuretic peptide is a predictor of anthracycline-induced cardiotoxicity. Acta Haematol 2000;104:158-63.

65. Soker M, Kervancioglu M. Plasma concentrations of NT-pro-BNP and cardiac troponin-I in relation to doxorubicin-induced cardiomyopathy and cardiac function in childhood malignancy. Saudi Med J 2005;26:1197-1202.

66. Roziakova L, Bojtarova E, Mistrik M, Dubrava J, Gergel J, Lenkova N, Mladosievicova B. Serial measurements of cardiac biomarkers in patients after allogeneic hematopoietic stem cell transplantation. J Exp Clin Cancer Res 2012;31:13. 
67. Pongprot Y, Sittiwangkul R, Charoenkwan P, Silvilairat S. Use of cardiac markers for monitoring of doxorubixin-induced cardiotoxicity in children with cancer. J Pediatr Hematol Oncol 2012;34:589-95.

68. Peetz D, Post F, Schinzel H, Schweigert R, Schollmayer C, Steinbach K, Dati F, Noll F, Lackner KJ. Glycogen phosphorylase BB in acute coronary syndromes. Clin Chem Lab Med 2005;43:1351-8.

69. Stejskal D, Lacnak B, Jedelsky L, Stepanova L, Proskova J, Solichova P, Kadalova L, Janosova M, Seitlova P, Karpisek M, Sprongl L. Use of glycogen phosphorylase BB measurement with $\mathrm{POCT}$ in the diagnosis of acute coronary syndromes. A comparison with the ELISA method. Biomed Pap Med Fac Univ Palacky Olomouc Czech Repub 2007;151:247-9.

70. O'Donoghue M, de Lemos JA, Morrow DA, et al. Prognostic utility of heart-type fatty acid binding protein in patients with acute coronary syndromes. Circulation 2006;114:550-7.

71. Shortt CR, Worster A, Hill SA, Kavsak PA. Comparison of hs-cTnl, hscTnT, hFABP and GPBB for identifying early adverse cardiac events in patients presenting within six hours of chest pain-onset. Clin Chim Acta 2013;419:39-41.

72. EIGhandour AH, ElSorady M, Azab S, EIRahman M. Human heart-type fatty acid-binding protein as an early diagnostic marker of doxorubicin cardiac toxicity. Hematology Reviews 2009;1:29-32.

73. Horacek JM, Tichy M, Jebavy L, Ulrychova M, Pudil R. Glycogen phosphorylase BB as a marker of cardiac toxicity during high-dose chemotherapy followed by hematopoietic cell transplantation. Ann Oncol 2007; 18:2041.

74. Horacek JM, Tichy M, Jebavy L, Pudil R, Ulrychova M, Maly J. Use of multiple biomarkers for evaluation of anthracycline-induced cardiotoxicity in patients with acute myeloid leukemia. Exp Onco 2008:30:157-9.

75. Horacek JM, Tichy M, Pudil R, Jebavy L. Glycogen phosphorylase BB could be a new circulating biomarker for detection of anthracycline cardiotoxicity. Ann Oncol 2008;19:1656-7.
76. Horacek JM, Tichy M, Pudil R, Jebavy L, Zak P, Ulrychova M, Slovacek $\mathrm{L}$, Maly J. Multimarker approach to evaluation of cardiac toxicity during preparative regimen and hematopoietic cell transplantation. Neoplasma 2008;55:532-7.

77. Horacek JM, Jebavy L, Ulrychova M, Tichy M, Pudil R, Zak P, Maly J. Glycogen phosphorylase BB could be a new biomarker for detection of cardiac toxicity during hematopoietic cell transplantation for hematological malignancies. Bone Marrow Transplant 2010;45:1123-4.

78. Horacek JM, Vasatova M, Tichy M, Pudil R, Jebavy L, Maly J. The use of cardiac biomarkers in detection of cardiotoxicity associated with conventional and high-dose chemotherapy for acute leukemia. Exp Oncol 2010;32:97-99.

79. Mercuro G, Cadeddu C, Piras A, Dessì M, Madeddu C, Deidda M, Serpe R, Massa E, Mantovani G. Early epirubicin-induced myocardial dysfunction revealed by serial tissue Doppler echocardiography: correlation with inflammatory and oxidative stress markers. Oncologist 2007;12:1124-33.

80. Mantovani G, Madeddu C, Cadeddu C, Dessì M, Piras A, Massa E, Serpe R, Antoni G, Mercuro G. Persistence, up to 18 months of followup, of epirubicin-induced myocardial dysfunction detected early by serial tissue Doppler echocardiography: correlation with inflammatory and oxidative stress markers. Oncologist 2008;13:1296-1305.

81. Nuver J, Smit AJ, Sleijfer DT, van Gessel Al, van Roon AM, van der Meer J, van den Berg MP, Burgerhof JG, Hoekstra HJ, Sluiter WJ, Gietema JA. Microalbuminuria, decreased fibrinolysis, and inflammation as early signs of atherosclerosis in long-term survivors of disseminated testicular cancer. Eur J Cancer 2004;40:701-6.

82. Vaughn DJ, Palmer SC, Carver JR, Jacobs LA, Mohler ER. Cardiovascular risk in long-term survivors of testicular cancer. Cancer 2008:112:1949-53.

83. Altena R, Perik PJ, van Veldhuisen DJ, de Vries EG, Gietema JA. Cardiovascular toxicity caused by cancer treatment: strategies for early detection. Lancet Oncol 2009;10:391-9. 